\title{
Tobacco Awareness with Socioeconomic Status and Pictorial Warning in Tobacco Cessation: An Exploratory Institutional Survey in a Semi-urban Population
}

\author{
Praveena Raman ${ }^{1}$, Raghuram Pitty ${ }^{2}$
}

\begin{abstract}
Aim: To explore the impact of socioeconomic status (SES) and/on the awareness of ill effects of tobacco on oral and general health and to evaluate the effectiveness of pictorial warning on tobacco cessation in a semi-urban population of South Chennai.

Materials and methods: This cross-sectional survey for 1 week was conducted using a two-stage sampling design, with a sample size of 300. New op patients constitute the first sampling design, and patients with history of any form of tobacco constituted second sampling design for the second part of the study. Following an informed consent in patient's own language, and as per inclusion criteria's, new op patient was interviewed with questionnaire 1, which comprised 27 closed-ended questions to assess subject's general awareness on tobacco, awareness of ill effects of tobacco on oral and general health, and their SES. Sociodemographic information such as age, sex, marital status, occupation, address, educational level, and family income per month was also recorded. Response categories for each of the questions were "yes", "no", and "don't know". The Questionnaire-2 comprised 8 closed-ended questions that assessed the subject's willingness to quit and to evaluate the effectiveness of pictorial warning on tobacco cessation, which was subjected only to those patients who had a history of tobacco usage which was recorded after completing the Questionnaire-1. This group formed the secondary sampling unit. Questionnaire-2 also included an individual suggestion for the preference of type of warning sign on the tobacco packet/sachet in the end. Statistically, Cronbach's a coefficient, one-way analysis of variance, Tukey HSD post hoc tests, and Chi-square test were used.

Results: On the whole, this study reported good awareness about harmful effects of tobacco. In all, $33.2 \%$ of respondents could not change after noticing the warning ads, $90.3 \%$ of our respondents are not aware that a professional help is available to motivate quitting. Smokers were more aware than smokeless tobacco users, and tobacco users recommended a greater area to be covered for pictorial warnings and to increase the frequency to change the pictorial warning signs.

Conclusion: Alarmingly high statistics and delayed presentation of oral and health hazards at the time of primary diagnosis underscores the need for an extensive awareness campaign on the issues related to ill effects of tobacco more focused on tobacco user's perspective and feedback. Clinical significance: Health awareness programs related to awareness of ill effects of tobacco should be tailor-made to the targeted population and should be more focused on the control of specific risk factors. Health warnings on tobacco packages that combine text and pictures, along with the frequent role of impact of mass media and campaigns on mouth self-examination and improvement in quality of life can effectively increase the general public awareness of the serious and deleterious health risks of tobacco use and to reduce its consumption.

Keywords: Audiovisual aids, Awareness, Cessation, Chewing tobacco, Mouth neoplasms, Mouth self-examination, Risk habits, Second-hand smoke, Socioeconomic status, Tobacco smoke, Tobacco use.

The Journal of Contemporary Dental Practice (2020): 10.5005/jp-journals-10024-2951
\end{abstract}

\section{INTRODUCTION}

Tobacco epidemic is one of the biggest public health threats the world has ever faced, killing more than 7 million people a year, a figure that is predicted to grow to more than 8 million a year by 2030 without intensified action. More than 6 million of these deaths are the result of direct tobacco use, while around 890,000 are the result of nonsmokers being exposed to second-hand smoke. ' India has $11.2 \%$ of the world's total smokers 1 million tobacco-related death every year. ${ }^{2}$ Tobacco users in any form develop serious illness, die prematurely, deprive their families of income, raise the cost of health care, and hinder economic development. ${ }^{3,4}$ Smokeless tobacco products and betel quid with or without tobacco are the major risk factors for oral cancer in India. Delayed presentation of oral cancer is mainly due to lack of awareness of the public about oral cancer and its associated risk factors. Health warnings on tobacco products can be very strong and cost-effective way of making people aware of hazardous effects of tobacco. Unlike many other products, tobacco packaging is not removed and discarded but is used as a container
${ }^{1}$ Department of Oral Medicine and Radiology, Sathyabama Dental College and Hospital, Chennai, Tamil Nadu, India

${ }^{2}$ Department of Oral Medicine and Radiology, SRM Dental College, Ramapuram, Chennai, Tamil Nadu, India

Corresponding Author: Praveena Raman, Department of Oral Medicine and Radiology, Sathyabama Dental College and Hospital, Chennai, Tamil Nadu, India, Phone: +91 7373230303, e-mail: drpraveena7@gmail.com

How to cite this article: Raman P, Pitty R. Tobacco Awareness with Socioeconomic Status and Pictorial Warning in Tobacco Cessation: An Exploratory Institutional Survey in a Semi-urban Population. J Contemp Dent Pract 2020;21(10):1122-1129.

Source of support: Nil

Conflict of interest: None

until the contents have been consumed; it thus provides high reach and frequency of exposure to users. ${ }^{5}$ 
As per article 11 of the World Health Organization Framework Convention on tobacco control (2003) guidelines, health warnings must be clear, large, rotating, and should cover at least $30 \%$ of the front and back of cigarette packages. Besides these minimum requirements, it must cover at least $50 \%$ or more of a package's principal surface area and may include pictures. ${ }^{6,7}$ India is the third among countries with largest pictorial warnings on tobacco products. ${ }^{8-11}$ Although pictorial warnings displaying oral cancer risk has been placed on tobacco products, yet these warnings are ignored, and tobacco is consumed on a large scale. The socioeconomic status (SES) is an important determinant of health, nutritional status, mortality, and morbidity of an individual, influencing the accessibility, affordability, acceptability, and actual utilization of available health facilities. ${ }^{12}$ Modified Kuppuswamy socioeconomic scale is commonly used to measure the SES in the urban communities. The scale includes the education, occupation of head of the family, and income per month from all sources. ${ }^{13}$ Early detection, which comprises screening of asymptomatic populations and increasing awareness of public regarding early signs and symptoms, increases the probability of cure. Little is known about the awareness regarding ill effects of tobacco in Indian population. Hence, this study was designed with an aim to explore the knowledge of ill effects of Tobacco and the Impact of pictorial warning on tobacco cessation with extensive objectives which includes to estimate the prevalence of tobacco users at a given period of time, to study the knowledge and awareness of the ill effects of tobacco on oral and general health, to estimate the pack years, to correlate the tobacco awareness with SES, and to evaluate the effectiveness of pictorial warning on tobacco cessation.

\section{Materials and Methods}

This study was designed and carried out at Department of Oral Medicine and Radiology, SRM Dental College and Hospital, Ramapuram, Chennai, Tamil Nadu, and was approved by the Institutional Ethical and Scientific Committee Board. The procedures followed were in accordance with the ethical standards of the responsible committee on human experimentation (institutional or regional) and with the Helsinki Declaration of 1975 that was revised in $2000 .^{14}$

\section{Sample}

This cross-sectional survey for one week was conducted using a two-stage sampling design. Sample size was determined by keeping the confidence level at $95 \%$ and an error rate of \pm 5 determining the need to include 300 participants. New op patients constitute the first sampling design, and patients with history of any form of tobacco constituted second sampling design for the second part of the study. All walk-in new op patients, visiting the department of oral medicine for the first time, above 18 years, and irrespective of their gender, were only included in the study. Those patients who were not willing to cooperate in the survey were excluded. Old op patients were excluded since they might already be visiting the tobacco cessation center in our department. No incentives were provided.

\section{Procedure}

A pilot study was conducted which not only helped to discern the sample size but also allowed assessment of the validity, reliability, and acceptability of the questionnaire. A group of 10 intern students from the study institution were trained how to administer the questionnaire by face-to-face interview and assist in case of reading/language problems or understanding of questions without prompting the answers. A written consent form was signed by all the participants of the study. For illiterate, the consent form was read and explained by the investigator, and their thumb impression was taken as their consent. Following the informed consent in patient's own language, and as per inclusion criteria's, new op patient was interviewed with adequate time and privacy in a separate hall to answer the questionnaires without the involvement of their accompanying relative. Sample questions was referred from literature, revised accordingly, and structured personally to meet our objectives. The questionnaire-1 comprised 27 closed-ended questions that assessed the subject's general awareness on tobacco, awareness of ill effects of tobacco on oral and general health, and their SES. Sociodemographic information, such as age, sex, marital status, occupation, address, educational level, and family income per month, was also recorded. Response categories for each of the questions were "yes", "no", and "don't know", and the respondents were expected to tick mark only the most appropriate one. These were coded as 1, 2, and 3, respectively.

The Questionnaire-2 comprised 8 closed-ended questions that assessed the subject's willingness to quit and to evaluate the effectiveness of pictorial warning on tobacco cessation, which was subjected only to those patients who had a history of tobacco usage which was recorded after completing the Questionnaire-1. This group formed the secondary sampling unit. Response categories for each of the questions were "yes", "no", and "don't know", and the respondents were expected to tick mark only the most appropriate one. These were coded as 1, 2, and 3, respectively. Questionnaire-2 also included an individual suggestion for the preference of type of warning sign on the tobacco packet/sachet in the end.

The results obtained from this survey will assist policy makers to implement an effective health education program and draft effective policies for tobacco, thereby helping to reduce the incidence rates of oral cancer.

\section{Assessment Strategy}

Cronbach's a coefficient was calculated to assess the validity and reliability of the Questionnaire. Cronbach's a was 0.89 , inferring a GOOD internal consistency. Pack-years was calculated by dividing the number of cigarettes smoked per day by 20 (the number of cigarettes in a pack) and then multiplying by the number of years smoked. Kuppusamy socioeconomic scale was used to access the SES of the patients.

\section{Measuring Tool}

Responses were scored in accordance with defined rules. Scores were treated for computer analysis (SPSS software). Chi-square test, one-way ANOVA, and Tukey HSD post hoc tests were performed. For the purpose of the study, only the awareness and SES with awareness were analyzed using SPSS software. Frequency and percentages were calculated to estimate the prevalence of smoking tobacco and chewing tobacco users.

\section{Results}

The study covered a total of 300 subjects. Of these, $75.7 \%$ were males and $24.3 \%$ were females. The mean age in males and females was found out to be 40.7 and 43.8 , respectively. With respect to the place of residence, $66.2 \%$ were from urban, while others $(33.8 \%)$ had a rural background but settled in Chennai. The percentage distribution according to the SES was found out to be $18.3 \%, 37.7 \%$, $12.0 \%, 17.7 \%$, and $14.3 \%$ in Class I (upper class), Class II (upper 


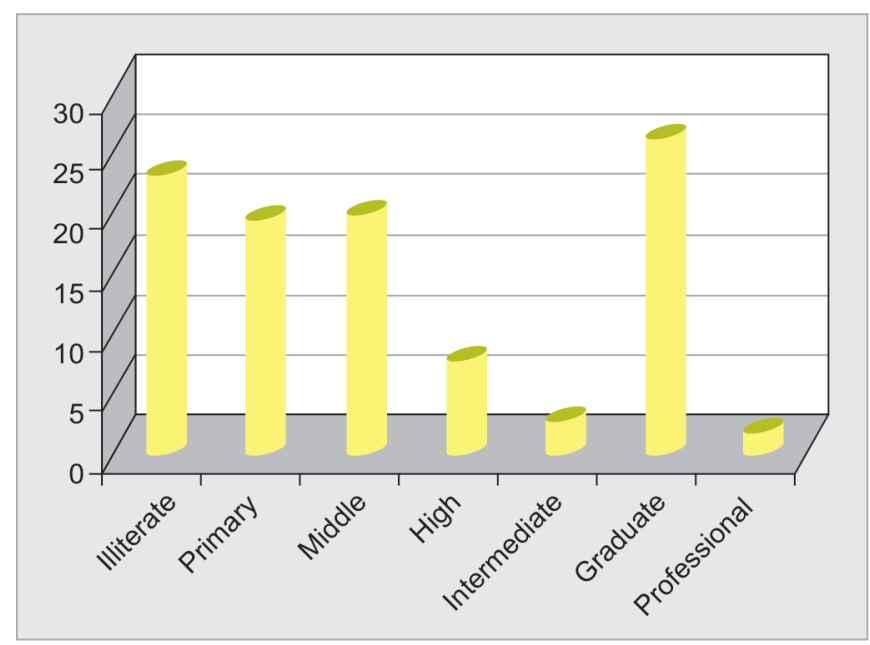

Fig. 1: Chart illustrating the percentage prevalence of education of our respondents

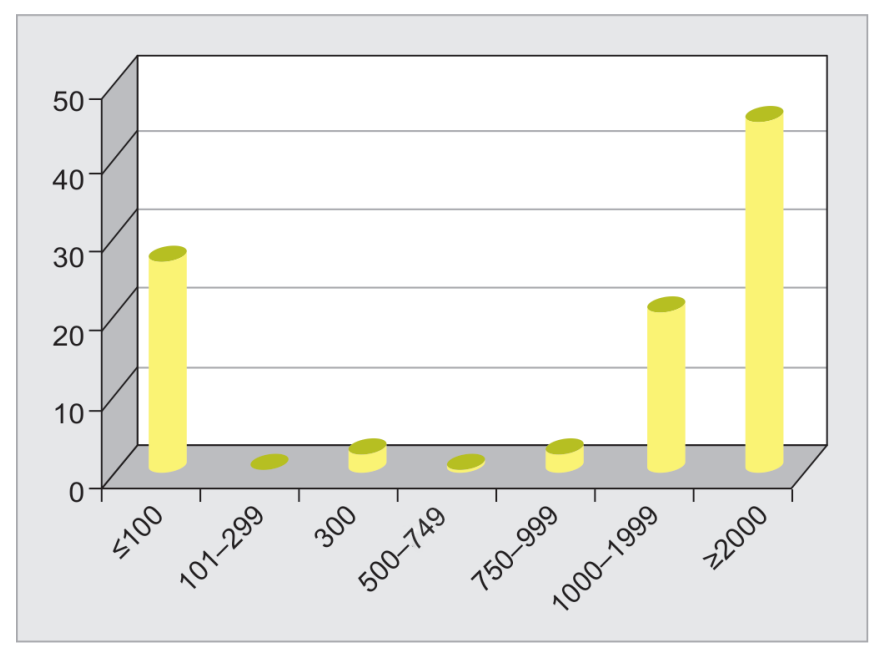

Fig. 3: Chart illustrating the percentage prevalence of income of our respondents

middle), Class III (lower middle), Class IV (upper lower), and Class $\mathrm{V}$ (lower), respectively. The percentage prevalence of education, occupation, and income of the respondents is illustrated in Figures 1 to 3, respectively.

\section{Interpretation of Results from Questionnaire-1}

The general awareness of tobacco was assessed via 11 closedended questions as shown in Table 1. The awareness seemed reasonable good. In all, $2.3 \%$ of respondent in Class V (lower) group were not aware that chewing tobacco and beetle nut is injurious to health, which is statistically not significant in Chi-square test, and $2.8 \%$ of Class III (lower middle) group were not aware that smokeless tobacco is dangerous even if consumed infrequently, which is statistically not significant in Chi-square test.

Q12: Have you ever practiced oral self-examination? If yes,

Q13: What have you noticed or experienced in your mouth? Full mouth; teeth, tongue, gums \& lips; teeth and tongue only; teeth only; never see.

In all the subclasses, $>30 \%$ of respondents have never practiced oral self-examination, and if practiced, they predominantly notice



Fig. 2: Chart illustrating the percentage prevalence of occupation of our respondents

their teeth only which is statistically significant. The awareness of tobacco on oral and systemic health was assessed via fourteen closed-ended questions. The awareness seemed reasonable good, but there exist a significant percentage of respondents who are not aware that tobacco use increases the risk of heart diseases, lung cancer, impotency, aging, and leads to health hazards in pregnancy as illustrated in Table 2 . In all, $11.4 \%$ of our total respondents were not aware that tobacco in any form causes oral precancer and oral cancer, which is statistically not significant in Chi-square test. In all, $92 \%$ of our total respondents agreed that change in lifestyle can reduce the risk of oral cancer, and $50.8 \%$ of our respondents in Class I (upper class) were not aware that smoking and smokeless tobacco can cause heart disease and lung cancer which is statistically not significant in Chi-square test.

Q25: Have you ever heard about passive smoking?

Q26: Do you think passive smoking is injurious to health?

Statistical significance was observed in question 25 , inferring that irrespective of the subclasses, there exist a group of respondents who have not heard about passive smoking. Around $10 \%$ of our population were not aware that tobacco causes dental problems (Table 2).

\section{Interpretation of Results from Questionnaire-2}

Prior to Questionnaire-2, personal habits of tobacco usage were recorded, along with number of cigarettes/day and number of tobacco packets/day with the duration of use to calculate packyears. Personal habits of tobacco usage were subdivided to nonsmokers/chewers, occasional smokers/chewers, regular chewers/ smokers, and ex-smokers/chewers. The percentage prevalence or distribution within smoking tobacco and smokeless tobacco group constitutes 9.3\% ex-smokers, 24.3\% regular smokers, $23.7 \%$ occasional smokers, $42.7 \%$ non-smokers; and $13.0 \%$ ex-chewers, $19.3 \%$ regular chewers, $21.3 \%$ occasional chewers, and $46.3 \%$ non-chewers, respectively. Statistical significance was observed in one-way ANOVA when compared between pack-years and SES as shown in Table 3, especially in chewing tobacco, inferring that chewing tobacco was prevailing in all the sub-classes. Tukey HSD post hoc tests also showed statistical significance in pack-years (chewing) between class II and class V. The percentage distribution of types of smoking and smokeless tobacco with respect to each socioeconomic class is illustrated in Figure 4. Table 4 shows 
Table 1: The eleven closed ended questions $(Q)$ to assess general awareness of tobacco

\begin{tabular}{|c|c|c|c|c|c|c|}
\hline \multirow[b]{2}{*}{ Questions } & \multicolumn{2}{|c|}{ Yes } & \multicolumn{2}{|c|}{ No } & \multicolumn{2}{|c|}{ Don't know } \\
\hline & $N$ & (\%) & $N$ & (\%) & $N$ & (\%) \\
\hline Q01. Are you aware that cigarette smoking is injurious to health? & 300 & 100.0 & 0 & 0.0 & 0 & 0.0 \\
\hline Q02. Are you aware that consuming beedi is harmful to health? & 300 & 100.0 & 0 & 0.0 & 0 & 0.0 \\
\hline Q03. Are you aware that chewing tobacco is injurious to health? & 298 & 99.3 & 1 & .3 & 1 & .3 \\
\hline Q04. Are you aware that beetle nut chewing is injurious to health? & 298 & 99.3 & 1 & 0.3 & 1 & 0.3 \\
\hline Q05. Are you aware that using beetle leaves with tobacco is injurious to health? & 297 & 99.0 & 2 & 0.7 & 1 & 0.3 \\
\hline Q06. Are you aware that pan masala is injurious to health? & 297 & 99.0 & 1 & 0.3 & 2 & 0.7 \\
\hline Q07. Are you aware that consuming gutka is injurious to health? & 297 & 99.0 & 0 & 0.0 & 3 & 1.0 \\
\hline $\begin{array}{l}\text { Q08. Are you aware that smoking tobacco is dangerous even if consumed } \\
\text { infrequently? }\end{array}$ & 299 & 99.7 & 0 & 0.0 & 1 & 0.3 \\
\hline $\begin{array}{l}\text { Q09. Are you aware that smokeless tobacco is dangerous even if consumed } \\
\text { infrequently? }\end{array}$ & 297 & 99.0 & 1 & 0.3 & 2 & 0.7 \\
\hline Q25. Have you ever heard of passive smoking? & 193 & 64.3 & 103 & 34.3 & 4 & 1.3 \\
\hline Q26. Do you think passive smoking is injurious to health? & 286 & 95.3 & 7 & 2.3 & 7 & 2.3 \\
\hline
\end{tabular}

Table 2: Awareness levels of tobacco on oral and general health

\begin{tabular}{|c|c|c|c|c|c|c|}
\hline \multirow[b]{2}{*}{ Questions } & \multicolumn{2}{|c|}{ Yes } & \multicolumn{2}{|c|}{ No } & \multicolumn{2}{|c|}{ Don't know } \\
\hline & $N$ & (\%) & $N$ & (\%) & $N$ & (\%) \\
\hline Q10. Is smoking tobacco linked with dental problems? & 285 & 95.0 & 8 & 2.7 & 7 & 2.3 \\
\hline Q11. Is smokeless tobacco linked with dental problems? & 285 & 95.0 & 7 & 2.3 & 8 & 2.7 \\
\hline Q14. Can smoking tobacco lead to oral precancer and cancer? & 283 & 94.3 & 2 & 0.7 & 15 & 5.0 \\
\hline Q15. Can smokeless tobacco lead to oral precancer and cancer? & 283 & 94.3 & 3 & 1.0 & 14 & 4.7 \\
\hline Q16. Can changes in lifestyle reduce the risk of developing oral cancer? & 278 & 92.7 & 5 & 1.7 & 17 & 5.7 \\
\hline Q17. Can smoking tobacco cause heart disease? & 198 & 66.0 & 21 & 7.0 & 81 & 27.0 \\
\hline Q18. Can smokeless tobacco cause heart disease? & 195 & 65.0 & 25 & 8.3 & 80 & 26.7 \\
\hline Q19. Can smoking tobacco cause lung cancer? & 275 & 91.7 & 7 & 2.3 & 18 & 6.0 \\
\hline Q20. Can smokeless tobacco cause lung cancer? & 266 & 88.7 & 12 & 4.0 & 22 & 7.3 \\
\hline Q21. Can smoking tobacco lead to early signs of aging? & 176 & 58.7 & 34 & 11.3 & 90 & 30.0 \\
\hline Q22. Can smokeless tobacco lead to early signs of aging? & 173 & 57.7 & 39 & 13.0 & 88 & 29.3 \\
\hline Q23. Can smoking tobacco lead to impotency and infertility? & 204 & 68.0 & 28 & 9.3 & 68 & 22.7 \\
\hline Q24. Can smokeless tobacco lead to impotency and infertility? & 201 & 67.0 & 32 & 10.7 & 67 & 22.3 \\
\hline Q27. Can passive smoking during pregnancy lead to health hazards? & 290 & 96.7 & 7 & 2.3 & 3 & 1.0 \\
\hline
\end{tabular}

Table 3: One way ANOVA to compare between SES

\begin{tabular}{|c|c|c|c|c|c|c|c|c|}
\hline Variable & SES & $N$ & Mean & Std. dev. & Min. & Max. & Fvalue & $p$ value \\
\hline \multirow[t]{6}{*}{ Age (years) } & Class-I & 55 & 33.98 & 10.904 & 20 & 74 & 14.573 & $<0.001$ \\
\hline & Class-II & 113 & 39.67 & 13.868 & 20 & 82 & & \\
\hline & Class-III & 36 & 47.25 & 14.983 & 22 & 75 & & \\
\hline & Class-IV & 53 & 38.83 & 16.336 & 20 & 80 & & \\
\hline & Class-V & 43 & 54.00 & 15.337 & 23 & 80 & & \\
\hline & Total & 300 & 41.44 & 15.447 & 20 & 82 & & \\
\hline \multirow[t]{6}{*}{ Pack years (smoking) } & Class-I & 26 & 0.9327 & 1.03932 & 0.05 & 5.00 & 3.911 & 0.005 \\
\hline & Class-II & 79 & 2.2424 & 4.25883 & 0.00 & 25.00 & & \\
\hline & Class-III & 31 & 3.0435 & 3.98195 & 0.20 & 15.00 & & \\
\hline & Class-IV & 24 & 3.2146 & 4.44817 & 0.10 & 14.00 & & \\
\hline & Class-V & 12 & 6.2333 & 5.71689 & 0.00 & 15.00 & & \\
\hline & Total & 172 & 2.6029 & 4.18013 & 0.00 & 25.00 & & \\
\hline \multirow[t]{6}{*}{ Pack years (chewing) } & Class-I & 14 & 0.6857 & 1.31111 & 0.05 & 5.00 & 7.755 & $<0.001$ \\
\hline & Class-II & 71 & 0.6077 & 0.84120 & 0.00 & 5.00 & & \\
\hline & Class-III & 30 & 2.0533 & 3.39193 & 0.05 & 15.00 & & \\
\hline & Class-IV & 22 & 2.8500 & 5.11699 & 0.05 & 20.00 & & \\
\hline & Class-V & 24 & 4.0604 & 4.06809 & 0.05 & 15.00 & & \\
\hline & Total & 161 & 1.7050 & 3.16394 & 0.00 & 20.00 & & \\
\hline
\end{tabular}






Fig. 4: Percentage prevalence of types of tobacco smokers and chewers with respect to socioeconomic class

statistical significance with ( $p$ value $<0.001$ ) between smoking and smokeless tobacco with SES.

The Questionnaire-2 comprised eight closed-ended questions to assess the subject's willingness to quit and to evaluate the effectiveness of pictorial warning on tobacco cessation as shown in Table 5 . In all, $97.4 \%$ of the respondents have tried to quit tobacco usage. $81.6 \%$ responded that the pictorial warning aid them in quitting, but $33.2 \%$ stated that there frequency did not change after noticing the warning adds. Chi-square test showed statistical significance between questions 28 and 29 with question 31 as showed in Table 6 . In all, $66.5 \%$ had a decreased frequency of usage after seeing the photos, and $90.3 \%$ of our respondents in Questionnaire-2 are not aware that a professional help is available to motivate quitting. Few suggestions from respondents regarding pictorial warning includes frequent change in warning signs every 3 months, strict government action to close tobacco industry, bigger sign boards near tobacco vendor areas, to increase the cost of tobacco products, self-control, banning adds on tobacco products, banning smoking in restaurants, in public places, discos/ bars/pubs, and to create public awareness by frequent theater plays and street plays.

After completion of the Questionnaire sessions, each patient was screened in the op for their respective chief complaint's to arrive at a treatment plan, and all the participants were made to watch an audio visual (AV) aid as a part of group health education session on the survey day.

The AV aid was on ill effects of tobacco on oral and general health, early signs and symptoms of oral cancer, associated risk factors for oral cancer, the importance of detecting the disease in its early stages, the benefits of quitting, and the importance of oral self-examination along with tobacco cessation counseling if they had any habit. All participants were encouraged to quit the usage of tobacco. An immediate feedback was collected for the interview and the AV sessions, and each respondent was provided an educational broacher having the content of the AV aid. Follow-up is done regularly to receive any additional opinion from patients and to ensure the reinforced points on tobacco awareness.

\section{Discussion}

There are only few studies conducted in the past to assess dental patient's knowledge and awareness of ill effects of tobacco on health. Moreover, most of the available studies have focused on either smoking or smokeless form of tobacco leading to oral cancer, and on knowledge and attitude of tobacco use among health professionals. ${ }^{15}$ In contrast to these studies, our study assessed awareness of ill effects of tobacco not only on oral health but also on general health, and after assessing their awareness, every tobacco user was subjected to Questionnaire 2 to evaluate the role of pictorial warning in tobacco cessation along with personal suggestions/opinion on warning signs. In this context, this study is an important addition to the existing literature. For effective implementation of tobacco control, knowledge regarding the awareness, attitudes, and practices of the population toward tobacco is necessary. ${ }^{16}$ Our study had $75.7 \%$ of males and $24.3 \%$ of females which is not in accordance with the study conducted by Tirukkovalluri et al. ${ }^{17}$ and Madappady et al., ${ }^{18}$ as the former study was conducted only on migrant male workers in Chennai, and the latter tobacco awareness study was conducted among medical students. In our study, awareness level is significantly higher in men than in women which is in accordance with Yang et al. ${ }^{19}$ However, this cannot be relied on the whole as majority of our study population were males. On the whole, this study reported good awareness about harmful effects of tobacco which is in accordance to the study conducted by Dhadwal and Kaushal in Shimla city ${ }^{16}$ and Tirukkovalluri et al. ${ }^{17}$ in Chennai population and not in accordance with the study conducted by Ibrahim et al. in Mangaluru, as the study was designed in a student population. ${ }^{20}$ The general awareness regarding ill effects of tobacco on oral and general health was observed to be more in Class I (upper class) and in the younger age-groups ( $<35$ years). It is also noteworthy that for increased level of education, there was increased awareness. The abovementioned findings should not be considered contradictory because the highest level of education assessed in this study were 'at least graduates' and by the time the subjects completed their 
Table 5: Questionnaire-2 comprising 8 closed-ended questions to assess the subject's willingness to quit and to evaluate the effectiveness of pictorial warning on tobacco cessation

\begin{tabular}{|c|c|c|c|c|}
\hline \multirow[b]{2}{*}{ Questions } & \multicolumn{2}{|c|}{ Yes } & \multicolumn{2}{|c|}{ No } \\
\hline & $N$ & (\%) & $N$ & (\%) \\
\hline $\begin{array}{l}\text { Q28. Have you ever tried in quitting } \\
\text { tobacco usage? }\end{array}$ & 191 & 97.4 & 5 & 2.6 \\
\hline Q29. Are you willing to quit? & 192 & 98.0 & 4 & 2.0 \\
\hline Q30. Do you buy cigarettes in packets? & 143 & 77.7 & 41 & 22.3 \\
\hline $\begin{array}{l}\text { Q31. Have you ever noticed the photos } \\
\text { on the cigarette packets? }\end{array}$ & 182 & 97.8 & 4 & 2.2 \\
\hline $\begin{array}{l}\text { Q32. Have you ever noticed the photos } \\
\text { on the chewing tobacco packets? }\end{array}$ & 194 & 99.0 & 2 & 1.0 \\
\hline $\begin{array}{l}\text { Q33. Do the photos aid you in cessa- } \\
\text { tion of tobacco usage? }\end{array}$ & 160 & 81.6 & 36 & 18.4 \\
\hline $\begin{array}{l}\text { Q34. Is your frequency of usage de- } \\
\text { creased after seeing the photos? }\end{array}$ & 131 & 66.8 & 65 & 33.2 \\
\hline $\begin{array}{l}\text { Q35. Do you know that a professional } \\
\text { help is available to motivate } \\
\text { quitting? }\end{array}$ & 19 & 9.7 & 176 & 90.3 \\
\hline
\end{tabular}

graduation they were mostly less than 35 years of age, which is in accordance with Agrawal et al. ${ }^{4}$ Furthermore, increased awareness of the younger age-group can also be attributed to the wide media exposure, usage of android phones with WhatsApp, and different anti-tobacco campaigns in recent years. Young people start smoking to enhance their social status, relieve anxiety, for stimulation, out of curiosity, or peer pressure with availability of extra money. Indeed, many smokers start smoking for entertainment purposes and curiosity for initiation. ${ }^{21}$ Around $20 \%$ of our study population were not aware that tobacco causes heart diseases and lung cancer, and around $10 \%$ were not aware that tobacco usage can cause infertility and impotence. Less than $10 \%$ are not aware that tobacco usage can cause dental problems. More than $40 \%$ of participants in class IV and V were aware that cigarette smoking, beedi, chewing tobacco, and beetle nut and leaves are injurious to health. According to Global Adult Tobacco Survey (GATS) 2016-2017, in India, $92 \%$ of adults believes that smoking causes serious illnesses and $96 \%$ believe that smokeless tobacco can cause serious illness. ${ }^{22}$ In our study, the prevalence of regular smokers was $24.3 \%$ which is in accordance to the study conducted by Sunil Kumar et al. ${ }^{23}$ In another study conducted by Kaur et al. in rural areas of Tamil $\mathrm{Nadu}$, it was observed that prevalence of tobacco use among males was $60.7 \%$, while $15.1 \%$ of females used tobacco at least once in a lifetime. However, this study cannot be compared with ours with respect to study duration, as ours is a 1-week survey. ${ }^{24} \mathrm{~A}$ much less prevalence of tobacco use was observed in a study conducted in rural, semi-urban, and urban areas of Chennai by Chockalingam et al. The overall prevalence in the rural area was only $23.7 \%$ which is almost coinciding with the results of our study. ${ }^{25}$ In our study, $>30 \%$ have never practiced oral self-examination which is in accordance with the study conducted by Pai et al..$^{15}$ Thus, majority of tobacco users were not paying attention to their oral health and are also not interested to look inside their oral cavity for any precancerous changes. This raises the high need for increasing the awareness among mass populations on effects of tobacco on oral, general health, and precancer. A study conducted by Elango et al. showed that awareness of oral cancer and its risk factors after introduction of mouth self-examination program was over $80 \% .{ }^{26}$ Our study 

cigarette packets?



showed significant difference between pack-years (chewing tobacco) and SES in ANOVA inferring that chewing tobacco was prevailing in all the sub-classes. Tukey HSD post hoc tests also showed statistical significance in pack-years (chewing) between class II and class V. More than $90 \%$ of our participants were aware that tobacco in any form can cause oral precancer and oral cancer which is in accordance with the study conducted by Agrawal. ${ }^{4}$ In our study, 92\% were aware that changes in lifestyle reduces the risk of oral cancer which is in accordance to the study conducted by Agrawal et al. ${ }^{4}$ These findings corroborate earlier findings, which report that mass media is a common source of information regarding oral cancer (Ariyawardana and Vithanaarachchi 2005; Petty and Scully 2007; Amarasinghe et al., 2010; Srikanth et al., 2011). In addition, housewives and retirees also spent more time socializing with either friends, neighbors, or community groups from who they could have heard about oral cancer. ${ }^{27}$ Prabhakar et al. conducted an awareness study on passive smoking in Chennai population and found out that the respondents were very well aware that passive smoking is spread through smell and the duration of exposure increases the intensity of passive smoking, which is not in accordance with our study. In our study, $34.3 \%$ have never heard about passive smoking. This difference could be attributed to the sample and methodology of both the studies, since ours is a face-to-face individualized study, and the former was designed through google forms, where participants could have cross checked and verified the answers through google search, leading to bias. ${ }^{28}$ Ogawa proved that pregnant women who have been exposed to passive smoking have low birth weight infants. ${ }^{29}$ Martin stated that Passive smoking has more effects in children than in adults. ${ }^{30}$ In all, $97.4 \%$ of the respondents to Questionnaire- 2 have tried to quit tobacco usage which is in accordance with the study conducted by Shomar et al. in Gaza, Palestine, ${ }^{21}$ and $90.3 \%$ of our respondents to Questionnaire-2 were not aware that a professional help is available to motivate quitting and whether such center existed which is also in accordance to the study conducted by Shomar et al. ${ }^{21}$ In general, smokers were more aware than smokeless tobacco users and tobacco users emphasized the importance of pictorial warning and recommended a greater area to be covered for pictorial warnings and to increase the frequency to change the pictorial warning signs. Also, people continue smoking despite the awareness of ill effect of usage due to their addiction which is in accordance to the study conducted by Srikanti Raghu in Guntur. ${ }^{31}$

Few suggestions from respondents regarding pictorial warning includes frequent change in warning signs every 3 months, to include more text, to increase the cost of tobacco products, self-control, etc. A successful image is about communication as most of the information transmitted to the brain is visual; it must tell the viewer the intended story through an entirely and solely visual means of communication. The visual portion has much more immediate impact than the text because text requires conscious processing and images do not, which facilitate to empower people to make strong associations between health messages and their perceptions. Integrating efforts of multidisciplinary teams are required to design more effective behavioral change communication strategies. There is a need to improve the awareness regarding deaddiction methods and programs. To date, far more attention has been focused on prevention rather than cessation, especially in low- and middle-income countries. The literature suggest that tobacco users would like to quit, although only less than $10 \%$ of them are successful in a given attempt, and a simple advice from a physician has been shown to increase abstinence rates when compared to those with "no advice". Thus, studies clearly indicate the challenge and need of raising knowledge and skills of faculties, students and the paramedical staff about the harmful effects of tobacco use and its cessation; and culturally appropriate style of counseling the patients. ${ }^{18,32}$

The limitations of this study include the sample size, points, and study duration and hence cannot be generalized to entire Chennai population. The sampling method might have introduced selection bias of the respondents. However, to minimize this, patients were selected only for 1 week to conduct this survey, considering that this could be one way of capturing different population demographics within a limited sampling time frame. Moreover, the sample captured was representative of the Tamil population where it is consisted of an ethnic profile that is in accordance with the country's population profile. Another limitation relates to the comprehensibility of certain phrases in the questionnaire, for example, "oral cancer" and "oral self-examination". However, to minimize this bias, a pretest was conducted. Since it was a quantitative study, few variables like reasons for tobacco usage 
could not be assessed properly. Also, smoking is a socially and culturally unacceptable habit; hence, people are less likely to report it which may lead to underreporting and in turn to decrease prevalence.

\section{Conclusion}

This study is a pioneering attempt at the grass root level in a high-risk semi-urban group, and the results clearly indicate that regardless of the good awareness of health problems related to tobacco use, the usage was high among our population in South Chennai, and tobacco awareness was relatively deficient in lower class, which is not satisfactory. This calls the need for more awareness programs in the targeted population specially directed toward the control of the risk factors. Health warnings on tobacco packages that combine text and pictures, along with role of mass media and oral self-examination can effectively increase public awareness of the serious health risks of tobacco use and to reduce its consumption.

\section{ACKNOWLedgments}

The author would like to thank Mr Boopathi for his valuable statistical analysis, Dr K Raman and Mr Karthikeya Murthy for their constant support and motivation in completing the article publication process.

\section{References}

1. WHO. Tobacco. Fact sheet. 2017. Available at: http://www.who.int/ mediacentre/factsheets/fs339/en/.

2. Mishra GA, Pimple SA, Shastri SS. An overview of the tobacco problem in India. Indian J Med Paediatr Oncol 2012;33(3):139-145. DOI: $10.4103 / 0971-5851.103139$.

3. Chapanda JP. Assessing the impact of tobacco farming in poverty alleviation: the case of small holder centenary farmers. 2016. Available at: http://ir.msu.ac.zw:8080/jspui/bitstream/11408/2168/1/julliet\%20 dissertation\%20final.pdf.

4. Agrawal M, Pandey S, Jain S, et al. Oral cancer awareness of the general public in Gorakhpur city, India. Asian Pacific J Cancer Prev 2012;13(10):5195-5199. DOI: 10.7314/APJCP.2012.13.10.5195.

5. Wakefield M, Letcher T. My pack is cuter than your pack. Tob Control 2002;11(2):154-156. DOI: 10.1136/tc.11.2.154.

6. World Health Organization. WHO Framework Convention on Tobacco Control. Geneva: World Health Organization; 2003. Available from: http://www.who.int/tobacco/framework/WHO_FCTC_english.

7. World Health Organization. MPOWER: a policy package to reverse the tobacco epidemic. Geneva: WHO; 2008.

8. Arora M, Tewari A, Nazar GP, et al. Ineffective pictorial health warnings on tobacco products: Lessons learnt from india. Indian J Public Health 2012;56(1):61-64. DOI: 10.4103/0019-557X.96978.

9. WHO Framework Convention on Tobacco Control. Geneva; 21 May, 2003. Available from: https://www.treaties.un.org/pages/ViewDetails. aspxsrc=TREATY\&mtdsg_no=IX-4\&chapter=9\&lang=en.

10. Government Releases New Pictorial Warnings for Tobacco Products. Available from: http://www.newindianexpress.com/ nation/2017/apr/04/government-releases-new-pictorial-warningsfor-tobaccoproducts-1589510.html.

11. India: $85 \%$ Pictorial Warnings Required, WHO Frame Work Convention on Tobacco Control, Implementation Database; 15 October, 2014. Available from: http://www.untobaccocontrol.org/impldb/updates/ page/13/.

12. Agarwal OP, Bhasin SK, Sharma AK, et al. A new instrument (scale) for measuring the socioeconomic status of a family: preliminary study. Indian J Community Med 2005;30:111-114.

13. Kumar N, Gupta N, Kishore J. Modified Kuppuswamy's socioeconomic scale. Indian J Public Health 2012;56(1):103-104. DOI: 10.4103/0019$557 X .96988$.
14. Declaration of Helsinki. World medical association of declaration of Helsinki. Ethical principles for medical research involving human subjects. Bull World Health Organ 2001;79(4):373-374.

15. Pai A, Arora A, Dyasanoor S. Awareness about effects of tobacco on oral and general health: a questionnaire study. Sch J App Med Sci 2014;2(4A):1190-1195.

16. Dhadwal DS, Kaushal K. Knowledge about the ill effects of tobacco use and COTPA act among adult male population of Shimla city. CHRISMED J Health Res 2016;3(4):279-283. DOI: 10.4103/23483334.190577.

17. Tirukkovalluri SS, Arumugam B, Gunasekharan N, et al. Social determinants in access to tobacco prevention and cessation support services among migrant construction workers in urban Chennai, India. J Family Med Prim Care 2020;9(4):1991-1998. DOI: 10.4103/ jfmpc.jfmpc_1072_19.

18. Madappady S, Kumar H, Jayaram S, et al. A study on awareness of health effects of tobacco consumption among medical students and impact of modular training. Int J Community Med Public Health 2018;5(9):4077-4085. DOI: 10.18203/2394-6040.ijcmph20183598.

19. Yang Y, Wang J-J, Wang C-X, et al. Awareness of tobacco-related health hazards among adults in china. Biomed Environmen Sci 2010;23(6):437-444. DOI: 10.1016/S0895-3988(11)60004-4.

20. Ibrahim A, Mathew SB, Arekal SS, et al. A study to assess the awareness of ill effects of tobacco among adolescents and young adults of Mangalore. NUJHS 2016;6(3):21-23. DOI: 10.1055/s-0040-1708656.

21. Abu Shomar RT, Lubbad IK, Ansari WEl, et al. Smoking, awareness of smoking-associated health risks, and knowledge of national tobacco legislation in Gaza, Palestine. Cent Eur J Public Health 2014;22(2):8089. DOI: 10.21101/cejph.a4005.

22. Global GATS. Adult Tobacco Survey: Fact Sheet, India 2016-17. 2017 http:// www.who.int/tobacco/surveillance/survey/gats/GATS_ India_2016-17_FactSheet.pdf.

23. Sunil Kumar D, Jom Thomas J, Mohandas A, et al. . Prevalence of substance use and awareness about its ill effects among people residing in a rural village in Chamarajanagara district, Karnataka. Clinical Epidemiology and Global Health 2020;8(2):442-445. DOI: 10.1016/j.cegh.2019.10.005.

24. Kaur P, Rao SR, Radhakrishnan E, et al. High prevalence of tobacco use, alcohol use and overweight in a rural population in Tamil Nadu, India. J Postgrad Med 2011;57(1):9. DOI: 10.4103/0022-3859. 74284.

25. Chockalingam K, Vedhachalam C, Rangasamy S, et al. Prevalence of tobacco use in urban, semi urban and rural areas in and around Chennai city, India. PLoS ONE 2013;8(10):e76005. DOI: 10.1371/journal. pone.0076005.

26. Elango KJ, Anandkrishnan N, Suresh A, et al. Mouth selfexamination to improve oral cancer awareness and early detection in a highrisk population. Oral Oncol 2011;47(7):620-624. DOI: 10.1016/j. oraloncology.2011.05.001.

27. Nabillah Ghani WM, Geraldine Doss J, Jamaluddin M, et al. Oral cancer awareness and its determinants among a selected malaysian population. Asian Pacific J Cancer Prev 2013;14(3):1957-1963. DOI: 10.7314/APJCP.2013.14.3.1957.

28. Prabhakar Y, Gayatri Devi R, Jyothipriya. A. Prevalence and awareness of health risks about passive smoking among Chennai population. Drug Invention Today 2019;12(5):877-879.

29. Ogawa H, Tominaga S, Hori K, et al. Passive smoking by pregnant women and fetal growth. J Epidemiol Community Health 1991;45(2):164-168. DOI: 10.1136/jech.45.2.164.

30. Martin T. How Second Hand Smoke Hurts Children. New York Times; 2018.

31. Raghu S, Venkata Rao M, Pulivarthhi SK, et al. Awareness of harmful effects of smoking among smokers. J Evolut Med Dent Sci 2015;4(80):13937-13942. DOI: 10.14260/jemds/2015/1985.

32. Raman P, Gayathri P. Dentist's delay or dexterity to diagnose the deadly: a clinicoradiological series of oral malignancies exhibiting varied presentations in the Tamil Nadu Rural Belt. Cureus 2019:11(2):e4051. DOI: 10.7759/cureus.4051. 